\title{
Diversitas Laba-laba (Predator Generalis) pada Tanaman Kacang Merah (Vigna angularis) di Kecamatan Tompaso, Kabupaten Minahasa \\ (The Diversity of Spider (Predator Generalis) in Kidney Bean (Vigna angularis) Plant Cultivated in Tompaso District, Minahasa Regency)
}

\author{
Redsway T. D. Maramis ${ }^{1)^{*}}$ \\ 1) Jurusan Hama dan Penyakit Tumbuhan Fakultas Pertanian Universitas Sam Ratulangi, \\ Manado \\ ^Email korespondensi: redsway_maramis@yahoo.com
}

Diterima 14 Januari 2014, diterima untuk dipublikasikan 26 Februari 2014

\begin{abstract}
Abstrak
Laba-laba (Araneae) adalah salah satu agen biologis yang sangat ampuh dalam pengendalian hama serangga pada ekosistem. Komposisi laba-laba yang dikumpulkan di kebun tanaman kacang merah terdapat 237 individu yang termasuk 19 genus, dan 10 famili. Hasil analisis indeks keanekaragaman labalaba pada tanaman kedelai menunjukkan pada fase awal pertumbuhan tanaman atau pada pengamatan pertama adalah yang terendah $\left(H^{\prime}=1,97\right)$, sedangkan tertinggi pada pengamatan kedua $\left(H^{\prime}=2,97\right)$, kemudian diikuti oleh pengamatan ketiga atau dalam fase pembuahan $\left(H^{\prime}=2,68\right)$.
\end{abstract}

\begin{abstract}
Spiders (Araneae) are one of the biological agents that are very potential for insect pest control in the ecosystem. The number of spiders that are collected in kidney bean plant field is 237 and consisted of 19 genus and 10 families. The result of spider diversity index analysis in kidney bean plant showed on the first step of plants growth or on the first observation are the lowest $\quad\left(H^{\prime}=1,97\right)$, whereas the highest on the second observation $\left(H^{\prime}=2,97\right)$, then followed by the third observation or in fertilization phase $\left(H^{\prime}=2,68\right)$.

Keywords : spiders, diversity, kidney bean
\end{abstract}

\section{PENDAHULUAN}

Di Sulawesi Utara, terdapat kurang lebih 17 jenis serangga hama yang menyerang pertanaman kacang-kacangan termasuk kacang merah, namun hanya beberapa jenis yang menimbulkan kerusakan yang berarti, di antaranya Etiella zinkenela, Riptortus linearis, Piezodorus hybneri, Nezara viridula, Riptortus linearis, Lamprosema indicata, dan Aphis sp. Marwoto et al. (1999) melaporkan kehilangan hasil akibat serangan hama untuk kacang kedelai dapat mencapai $80 \%$, bahkan sampai puso bila tidak dilakukan pengendalian. Di Sulawesi Utara, pengendalian terhadap hama- hama kacang merah masih sangat tergantung pada insektisida, karena belum ada cara lain yang mampu menurunkan populasi hama dan kerusakan tanaman. Alternatif yang dapat ditempuh dalam pengendalian serangga hama adalah pemanfaatan musuh alami. Namun sejauh ini data musuhmusuh alami yang berasoiasi pada ekosistem tanaman kacang merah di Sulawesi Utara belum banyak dikaji.

Salah satu musuh alami yang penting pada ekosistem tanaman kacang merah adalah laba-laba. Laba-laba dikenal sebagai predator generalis (umum) terhadap serangan hama. Laba-laba adalah 


\section{JURNAL BIOSLOGOS, FEBRUARI 2014, VOL. 4 NOMOR 1}

agen pengendalian hayati yang potensial terhadap hama tanaman. Banyak jenis laba-laba yang telah dilaporkan memangsa beragam jenis hama pada tanaman pertanian. Pada tanaman kacang-kacangan ditemukan beragam jenis laba-laba yang potensial untuk dimanfaatkan secara optimal untuk menekan perkembangan populasi hama (Horn 1988).

Pengendalian secara alamiah atau biologi terhadap hama dan penyakit tanaman merupakan salah satu cara untuk mengurangi resiko terhadap kesehatan dan kerusakan lingkungan. Laba-laba (Araneae) adalah salah satu agen biologi yang sangat potensial dalam pengendalian hama serangga pada ekosistem pertanian. Kepadatan populasi dan kelimpahan spesies komunitas laba-laba (biodiversity) pada ekosistem alamiah dan termasuk pertanian adalah tinggi (Platnick 2009). Laba-laba adalah predator generalis berperan penting dalam mereduksi, dan mencegah terjadinya ledakan hama secara alami pada budidaya tanaman pertanian serta berkontribusi pada keanekaragaman hayati (Oberg 2007). Oleh karena itu laba-laba dapat dipertimbangkan membantu pengaturan (regulate) kepadatan populasi serangga hama. Sebagai predator generalis, laba-laba dianggap lebih efisien daripada predator spesialis untuk menekan hama pada habitat yang sering mengalami gangguan seperti praktek budidaya tanaman pertanian (Wissinger 1997). Predator generalis dapat didukung oleh mangsa alternatif tanpa serangga herbivora (Chen and Wise 1999).

Laba-laba terutama memakan serangga dan artropoda lainnya, seperti Colembola, Diptera, Homoptera, Orthoptera, Coleoptera, Lepidoptera dan juga laba-laba. Berbagai jenis laba-laba menerapkan strategi yang berbeda untuk menangkap mangsanya. Beberapa jenis laba-laba membuat jaring sebagai perangkap mangsa dan jenis ini umumnya memiliki kaki yang panjang dan tipis atau mengecil, yang cocok untuk membuat jaring. Selain untuk menangkap mangsa, jaring juga berfungsi sebagai tempat tinggal. Laba-laba lainnya berburu atau berjalan, melompati mangsanya, menunggu dengan membiarkan mangsanya mendekat kepadanya. Komunitas laba-laba berhubungan erat dengan karakteristik komunitas tumbuhan (Foelix 1996). Laba-laba pembuat jaring berhubungan langsung dengan arsitetur vegetasi karena merupakan prasyarat untuk dapat menempatan jaringnya. Jumlah secara dramatis meningkat ketika lapisan serasah semakin tebal dan lembab, karena lebih banyak tersedia mangsa, tempat untuk bersembunyi dan terhindar dari suhu ekstrim (Rysptra et al. 1999). Struktur lansekap, tipe habitat, periode pertumbuhan tanaman, juga berperan pada diversitas fauna spesies laba-laba (Suana et al. 2004).

Menurut Susilo (2007), familifamili dari Ordo Araneae (laba-laba) yang banyak dijumpai pada agroekosistim dan berperan penting dalam pengendalian alami serangga hama adalah spesies-spesies anggota dari Araneidae, Lyniphiidae, Lycosidae, Oxyopidae, Saltecidae, Tetragnatidae, dan Thomosidae. Laporan-laporan tentang studi yang berhubungan dengan laba-laba pada agroekosistem di Sulawesi Utara belum banyak dilakukan. Sebagai salah satu referensi adalah studi yang dilakukan oleh Russe-Smith dan Strok (1994), diidendifikasi terdapat 1642 individu yang berasal dari Clubionidae, Castianeirinae, Theridiidae, Salticidae, Araneidae, dan Lyniphiidae. Kelimpahan spesies tertinggi pada ketinggian 
$400 \mathrm{~m}$ yang terdapat 69 sepsies dengan jumlah 648 individu; $6 \%$ dari total laba-laba adalah Clubionidae dan Araneidae. Pada ketinggian $1150 \mathrm{~m}$, tertinggi Lyniphidae, kemudian Clubionidae 13\% spesies. Lansekap pertanian di Kabupaten Minahasa khususnya di wilayah Tompaso cukup beragam walaupun umumnya tanaman yang dibudidayakan adalah tanaman pangan dan sayur-sayuran. Ekosistim pertanian seperti ini dapat dikatakan sering terjadi perubahan temporal, selain itu juga karakteristrik tanaman, pola tanam, dan lingkungan dapat berbeda-beda. Hal ini kemungkinan berpengaruh pada kelimpahan, keanekaragaman, dan komunitas laba-laba, sehingga merupakan pertimbangan penting dalam rangka merancang strategi pengelolaan hama tanaman. Oleh karena itu, penelitian ini dirancang untuk mengetahui jenis dan kelimpahan, serata diversitas labalaba tanaman kacang merah. Kacang merah merupakan komoditi penting dalam pertanian di Minahasa sehingga penelitian tentang pengendalian hama tanaman ini sangat penting.

\section{METODE PENELITIAN Waktu dan Tempat}

Penelitian berlangsung selama 4 bulan, mulai bulan Agustus 2013 sampai dengan November 2013. lokasi penelitian di wilayah Tompaso, Kabupaten Minahasa, Sulawesi Utara, dengan ketinggian tempat sekitar $700 \mathrm{~m}$ diatas permukaan laut. Di lokasi penelitian ini ditanam berbagai jenis tanaman seperti; padi sawah, jagung, kacang merah, dan tanaman sayur-sayuran seperti; tanaman tomat, bawang daun, bawang merah, cabe dan jenis tanaman kubis-kubisan. Penelitian dilakukan tanaman kacang merah (Vigina angularis) (Wild).

\section{Teknik Pengambilan Sampel}

Terdapat tiga lokasi areal tanaman kacang merah yang menjadi lokasi pengambilan sampel dengan jarak masing-masing lokasi kurang lebih $300 \mathrm{~m}$. Pengambilan sampel laba-laba dilakukan di setiap sudut areal penanaman kacang merah. Luas masing-masing pengambilan sampel atau pengamatan laba-laba $4 \times 4$ meter persegi. Jadi terdapat 12 lokasi tempat pengambilan contoh atau pengamatan laba-laba.

Pengamatan aktivitas laba-laba kursorian atau yang beraktivitas di permukaan tanah dilakukan dengan perangkap jebak yang terbuat dari botol pelastik bekas air mineral (200 $\mathrm{ml})$ dengan diameter permukaan 7 $\mathrm{cm}$.

Botol plastik ditanam ke dalam tanah hingga permukaan gelas rata dengan permukaan tanah, kemudian dimasukan larutan alkohol $80 \%$. Perangkap jebak diletakkan disetiap sudut areal pertanaman kacang merah. Pengambilan contoh dilakukan setelah terpasang selama $3 \times 24$ jam. Perangkat jebak di bagian atasnya diberi perlindung yang terbuat dari seng, agar supaya terlindungi dari masuknya air jika terjadi hujan dan juga bahan-bahan lainnya. Perangkap ini digunakan untuk menangkap laba-laba yang bergerak aktif dipermukaan tanah yang diharapkan lewat pada perangkap sehingga terjebak masuk ke dalam gelas. Laba-laba yang terperangkap dipisahkan dari cairan dan kotoran yang terdapat di dalam botol perangkap jebak.

Untuk pengambilan sampel laba-laba yang terdapat di tanaman dilakukan dengan penangkapan langsung. Pengamatan dilakukan 15 hari sesudah tanaman sampai tanaman berbuah. Pengambilan contoh laba-laba dilakukan sebanyak tiga kali. Semua sampel atau contoh laba-laba yang tertangkap dengan menggunakan alat perangkap jebak dan 


\section{JURNAL BIOSLOGOS, FEBRUARI 2014, VOL. 4 NOMOR 1}

penangkapan langsung dibawa ke Laboratorium Entomologi dan Hama Tumbuhan, Fakultas Pertanian UNSRAT Manado untuk dihitung populasi dan diidentifikasi morfologinya di bawah mikroskop. Indentifikasi laba-laba menggunakan kunci deteminasi oleh Barrion and Litsinger (1995), Indentifikasi akan dilakukan untuk family, genus, dan jika dapat sampai spesies.

\section{Analisis Data}

Analisis keanekaragaman jenis laba-laba sesuai dengan fase pertumbuhan tanaman dengan menggunakan indeks ShannonWiener. Metode ini sensitif terhadap perubahan kelimpahan spesies yang jarang dalam suatu komonitas (Krebs 1989, Sudhikumar et al. 2005). Untuk analisis statistik dilakukan secara deskriptif.

\section{HASIL DAN PEMBAHASAN Jenis dan Kelimpahan Laba-laba di Pertanaman Kacang Merah}

Pengumpulah/koleksi dengan perangkap jebak dan penangkapan langsung (hand picking) di lapangan yang kemudian diidenntifikasi dan dihitung kelimpahan populasi labalaba di laboratorium jurusan Hama dan Penyakit Tumbuhan Fakultas pertanian UNSRAT menunjukan hasil yang beragam (Tabel 1). Komposisi laba-laba yang dikoleksi pada areal penanaman tanaman kacang merah total terdapat 237 individu yang terdiri dari 19 genus, dan 10 famili. Pada pengamatan pertama terdapat 52 individu 11 genus, dan 8 famili, untuk pengamatan kedua terdapat 94 individu, 19 genus, dan 10 famili, sedangkan pada pengamatan ketiga ditemukan 91 individu, 19 genus, dan 10 famili (Tabel 1).

Jenis laba-laba yang paling dominan adalah dari famili Lycosida yang terdiri dari genus Atoria, Pardosa, Trochosa. Lycosida adalah laba-laba srigala (wolf spiders) atau laba-laba tanah (groud spiders) dan juga laba-laba ini tidak membuat jaring untuk menangkap mangsanya. Laba-laba ini terkenal sangat aktif di atas permukaan tanah, dan sering juga memanjat tanaman terutama pada vegetasi yang rendah untuk mencari makanan sebagaimana pada tanaman kacang merah. Tetapi juga laba-laba ini lebih menyukai daerah-daerah yang terbuka seperti yang terlihat pada Tabel 1. Terlihat lebih dominan ditemukan pada fase pertumbuhan awal saat kanopi antara tanaman belum menyatu atau bersentuhan.

Araneidae yang terdiri genus Araneus sp., Cyclosa sp., dan neoscona sp. Merupakan jenis labalaba paling dominan setelah famili Lycocidae. Araneidae atau laba-laba bolah (orbspiders) bertubuh relatif bulat dengan warna-warni yang sangat mencolok. Pada tanaman kacang merah laba-laba ini membuat jaring-jaring berbentuk lingkaran yang ditenum diantara ranting, cabang atau anrata tanaman untuk menangkap ngengat dan serangga hama lain. Umumnya konstruksi laba-laba ini diletakan secara vertikal di antara tanaman kacang merah.

Mitidae dan Theridiidae merupakan laba-laba yang dominan ketiga setelah Lycosidae dan Araneidae. Mitidae terdiri dari genus Leucage sp., Msida sp., dan Tylorida sp. Laba-laba Ini termasuk yang membuat jaring berbentuk bulat (orb waver) untuk menangkap serangga. Konstuksi jaring laba-laba umumnya ditenun di antara tajuk-tajuk tanaman kacang merah dan diletakkan secara horizontal.

Theridiidae beranggotakan genus Chrysso, dan Coleosoma. Laba-laba ini juga membuat jaring dengan beberapa bentuk untuk menangkap mangsa. Jaringjaringnya diletakan di antara dedaunan, ranting atau percabangan tanaman kacang merah. 
Tabel 1. Jenis dan populasi laba-laba yang dikoleksi pada tanaman kacang merah di Tompaso, Kabupaten Minahasa

\begin{tabular}{|c|c|c|c|c|c|}
\hline \multirow[t]{2}{*}{ Famili } & \multirow[t]{2}{*}{ Genus/spesies } & \multicolumn{4}{|c|}{ Pengamatan } \\
\hline & & I & II & III & Total \\
\hline \multirow[t]{3}{*}{ Araneidae } & Araneus sp. & 0 & 9 & 11 & 20 \\
\hline & Cyclosa sp. & 0 & 7 & 9 & 16 \\
\hline & Neoscona sp. & 2 & 5 & 3 & 10 \\
\hline \multicolumn{2}{|l|}{ Total } & 2 & 21 & 23 & 46 \\
\hline Clubionidae & $\begin{array}{l}\text { Cheiracanthium } \\
\text { sp. }\end{array}$ & 0 & 2 & 2 & 4 \\
\hline \multicolumn{2}{|l|}{ Total } & 0 & 2 & 2 & 4 \\
\hline \multirow[t]{2}{*}{ Linyphiidae } & Atypena sp. & 1 & 3 & 4 & 8 \\
\hline & & 1 & 3 & 4 & 8 \\
\hline \multirow[t]{3}{*}{ Lycosidae } & Artoria sp. & 4 & 3 & 0 & 7 \\
\hline & Pardosa sp. & 15 & 11 & 6 & 32 \\
\hline & Thochosa sp. & 12 & 10 & 3 & 25 \\
\hline \multicolumn{2}{|l|}{ Total } & 31 & 24 & 9 & 64 \\
\hline \multirow[t]{3}{*}{ Mitidae } & Laucauge sp. & 4 & 7 & 9 & 20 \\
\hline & Mesida sp. & 1 & 4 & 4 & 9 \\
\hline & Tylorida sp. & 0 & 3 & 3 & 6 \\
\hline \multicolumn{2}{|l|}{ Total } & 5 & 14 & 16 & 35 \\
\hline \multirow[t]{2}{*}{ Osyopidae } & Oxyopes sp. & 0 & 4 & 7 & 11 \\
\hline & & 0 & 4 & 7 & 11 \\
\hline \multirow[t]{3}{*}{ Salticidae } & Cosmophasis sp. & 0 & 3 & 2 & 5 \\
\hline & Gungus sp. & 0 & 0 & 3 & 3 \\
\hline & Plexppus sp. & 0 & 1 & 4 & 5 \\
\hline \multicolumn{2}{|l|}{ Total } & 0 & 4 & 9 & 13 \\
\hline Tetragnathidae & Tetragnatha sp. & 2 & 5 & 6 & 13 \\
\hline \multirow{3}{*}{ Theridiidae } & & 2 & 5 & 6 & 13 \\
\hline & Chrysso sp. & 5 & 6 & 7 & 18 \\
\hline & Coleosama sp. & 4 & 7 & 6 & 17 \\
\hline \multicolumn{2}{|l|}{ Total } & 9 & 13 & 13 & 35 \\
\hline Zodariidae & Langbina sp. & 2 & 4 & 2 & 8 \\
\hline $\begin{array}{ll} & \text { Total } \\
\end{array}$ & & 2 & 4 & 2 & 8 \\
\hline \multicolumn{2}{|l|}{$\begin{array}{l}\text { Total } \\
\text { Total Keseluruhan }\end{array}$} & 52 & 94 & 91 & 237 \\
\hline
\end{tabular}
mengikuti umur tanaman kacang merah pada umum 15 hari sesuda tanam atau pengamatan pertama sampai tanaman berbuah yaitu pengamatan ketiga. Kelimpahan populasi tertinggi terdapat pada pangamatan kedua, kemudian iikuti pengamatan ketiga dan terendah pada pengamatan pertama (Tabel 1). Perbedaan ini terjadi pada pengamatan kedua disebabkan bertambahnya ukuran tajuk tanaman memberikan relung yang luas untuk

\section{Diversitas Laba-laba pada} Tanaman Kacang Merah

Hasil analisis indeks diversitas labalaba pada tanaman kacang merah yang berdasarkan fase pertumbuhan tanaman, menunjukan pada awal pertumbuhan tanaman atau pada pengamatan pertama terendah $(\mathrm{H}=$ 1,97), sedangkan yang tertinggi pada pengamatan kedua $(\mathrm{H}=2,79)$, kemudian diikuti pengamatan ketiga atau pada fase pembuahan $(\mathrm{H}=$ 
Tabel 2. Indeks diversitas laba-laba menurut fase pertumbuhan tanaman kacang merah di Tompaso, Kabupaten minahasa.

\begin{tabular}{l}
\hline Pengamatan \\
\hline 1 \\
2 \\
3 \\
\hline 4,68$) \quad$ Jabel 2). Perbedaan \\
diversitas laba-laba ini meningkat \\
sesuai dengan pertumbuhan \\
tanaman. Hal ini terjadi karena \\
struktur tanaman pada awal \\
pertumbuhan tanaman masih \\
sederhana, sedangkan pada fase \\
pertumbuhan pada pengamatan \\
kedua dan ketiga fase pertumbuhan \\
sangat kompleks. Semakin luas \\
kanopi tanaman, maka jumlah laba- \\
laba semakin meningkat. Struktur \\
tanaman yang kompleks akan \\
memberikan ruang yang luas untuk \\
didiami oleh spesies laba-laba \\
tertentu. Contoh laba-laba dari \\
anggota-anggota dari spesies \\
Araneidae yang memerlukan tajuk \\
tanaman yang luas untuk meletakan \\
konstuksi jaring untuk menangkap \\
mangsanya.
\end{tabular}

\section{KESIMPULAN}

Komposisi laba-laba yang dikoleksi pada areal penanaman tanaman kacang merah total terdapat 237 individu yang terdiri dari 19 genus, dan 10 famili. Pada pengamatan pertama terdapat 52 individu 11 genus, dan 8 famili, untuk pengamatan kedua terdapat 94 individu, 19 genus, dan 10 famili, sedangkan pada pengamatan ketiga ditemukan 91 individu, 19 genus, dan 10 famili. Jenis laba-laba yang paling dominan adalah dari famili Lycosida, yang diikuti famili Araneidae, kemudian Mitidae dan Theridiidae.

Hasil analisis indeks diversitas laba-laba pada tanaman kacang merah yang berdasarkan fase pertumbuhan tanaman, menunjukkan pada awal pertumbuhan tanaman atau pada pengamatan pertama terendah $(\mathrm{H}=$ 1,97), sedangkan yang tertinggi pada pengamatan kedua $(\mathrm{H}=2,79)$, kemudian diikuti pengamatan ketiga atau pada fase permbuahan $(\mathrm{H}=$ $2,68)$.

\section{DAFTAR PUSTAKA}

Barrion AT, Lissinger JA (1995) Riceland spiders of South and Southeast Asia. IRRI $\mathrm{CABI}$, Manila.

Biere J, Uetz G (1981) Web orientation in the spider Micrathena gracilis (Araneae: Araneidae). Ecology 62:261267

Chen B, Wise DH (1999) Bottom up limitation of Predaceous arthopoda in detitus-based terrestrial food web. Ecology 80:761-772

Fagan WP, Hakim AL, Yuliyantiningsih S (1998) Interaction betwen biological control efforts and insecticide application in tropical rice agroecosystems: potential role of intraguild predation. Biological control: theory and applications in pest management. 13:121-126

Foelix RF (1996) Biology of spider. Oxford University Press, Madison Avenue, New York. 10016 
Greenstone $\quad \mathrm{MH}$

(1979)

Spiderfeeding behavior

optimizes dietary essential

amino acid compositon.

Nature 282:501-503

Horn DJ (1988) Ecological approach to pest management. The Fullford Press. New York.

Hurd LE, Fagan WF (1992) Cursorial spiders and succession: Age or habitat structure? Oecologia 92:215-221

Janetos AC (1982) Spiders. Foraging tactics of two guild of web-spinning spiders. Behav Ecol Sosiobiol 10:1917

Johnson ML (1999) Comparing predatory insectcs of Helicoverpa sp. In Australia Cotton: Approaches to measuring prey consumption. PhD Thesis. University of New England. Armidale, Australia

Jones-Welters L (1993) A jamping spider feeding on insect egg. Newslett Br Arachnol Soc 6:5

Krebs KC (1989) Ecological methodology. Harper \& Row, New York.

Lang A, Filser J, Hensckel JR (1999) Predation by ground beetles and wolf spiders on herbivorous insects in a maize crop. Agric Ecosyst Environ 72:189-199

Langellotot GW, Denno RF (2004) Response of invertebrate natura, enemies to complexstructured habitat: a metaanalytical

Oecologia 139:1-10

Lesar CD, Unzicker JD (1987) Life history, habits, and prey preferences of Tetragnatha laboriosa (Araneae: Tetragnathidae). Environ Entomol 7:879-884

Letoumeu DK, Goldstein B (2001) Pest damage and arthropoda community structure in organic vs conventional tomato production in California. J Applied Ecol 38:557-570

Luczeck J (1979) Spiders in agrocoenoses. Polish Ecol Stud 5:151-200

Marc P, Canard A, Ysnel F (1999) Spiders (Araneae) useful for pest limitation and bioindication. Agric Ecosyst Environ 74:229-273

Marwoto, Suharsono, Supriyatin (1999) Hama kedelai komponen pengendalian hama terpadu. Monograf Balitkabi

Nentwig W (1987) The prey of spiders. Dalam: Nentwig W (Ed) Ecophysiology of spiders. Springer-Verlag, Berlin, New York. pp. 249263

Nyffeler M (1999) Prey selection of spiders in the field. $\mathrm{J}$ Arachnol 27:317-324

Oberg S (2007) Spider in the agriculture landscape. Diversity, recolonitation, and boddy condition. Dortoral Thesis. Swedish University of Agricultural Sciences. Uppsala.

Platnick, Norman I (2009) The World spider catalog. Version 9.5. America Museum of Natural History

Raizer J, Amaral MEC (2001) The structural complexity of aquacultural macrophytes explain the diversity of associated spider assemblages? J Arachnol 29:227-237

Riechert SE, Gillespie G (1986) Habitat choice and utilization in web-building spider. Dalam: Sher (Ed) Spiders: Web, behavior, and evolution. Stanford University Press, Stanford

Roberts MJ (1995) Spider of Britain \& nothern Europe. Collins 
40 JURNAL BIOSLOGOS, FEBRUARI 2014, VOL. 4 NOMOR 1

Field Guide. Herper Collins

memberdayakan

musuh

Publishers

Ruppet EE, Fox RS, Bernes RD ( alami hama tanaman. Graha IImu.

2004) Invertebrate zoology.

Edisi ke-7. Brooks/Cole

Russell-Smith A, Stork NA (1994)

Abudance and diversity of spider from the canopy of tropical rainforest with particular reference to Sulawesi, Indonesia. J Tropical Ecol 10:545-558

Symonds WOC, Sunderland KD, Greenstone (2002) Can generalis predators be effective biocontrol agents? Annu Rev Entomol 47:561594

Suana IW, Solihin DD, Buchari D, Manuwoto S, Triwidodo $\mathrm{H}$ (2004) Komunitas laba-laba pada lansekap persawahan di Cianjur. Hayati11:145-152

Sudnikumar AV, Mathew MJ, Sunis EA, Sebastian (2005) Seasonal variation abundance in Kuttanad rice agroecosystem. Acta Zool Bulgaria 1:181-190

Susilo FX (2007) Pengendalian hayati

dengan

Toft S (1995) Value of the aphid Rhopalosiphum padi as food for cereal spiders. J Appl Ecol 32:552-560

Webb NR, Clarke RT, Nicolas JT (1984) Invertebrate diversity on fragmented Calluna Heathland: Effects of surrounding vegetation. $\mathrm{J}$ Biogegr 11:41-46

Wiedenmann RN, Smith Jr. JW (1997) Attribute of natural enemies in ephemeral crop habitat. Biological Control.

Wise DH (1993) Spiders in ecological webs. Cambridge Univ. Press. Cambridge, U.K.

Wissinger SA (1997) Cyclic colonization in predictability ephemeral habitat: A template for biological control in annual crop system. Biological Control 10:4-5

Young OP, Edwards GB (1990) Spiders in United States field crops and their potential effect on crop pests. J Arachnol 18:1-27 